\title{
Biventricular arrhythmogenic cardiomyopathy: a paradigmatic case
}

\author{
M. Calcagnino ${ }^{1 *}$, G. Girardengo ${ }^{1,2}$, A. Ghidoni ${ }^{3,4}$, M. C. Kotta ${ }^{3,4}$, A. Di Blasio ${ }^{3}$, M. Revera ${ }^{5}$, \\ C. Torlasco ${ }^{5,6}$, G. Perego ${ }^{5}$, B. Bilo ${ }^{5}$, F. Dagradi ${ }^{1}$, L. Crotti $^{1,4,7}$, G. Parati $^{5,6}$, \\ P. J. Schwartz ${ }^{1}$, and F. Cecchi ${ }^{1,5}$ \\ ${ }^{1}$ Laboratory of Cardiovascular Genetics, Center for Cardiac Arrhythmias of Genetic Origin, IRCCS Istituto Auxologico \\ Italiano, Milano, Italy \\ ${ }^{2}$ Department of Cardiovascular Medicine, University of Pavia, Pavia, Italy \\ ${ }^{3}$ Laboratory of Cardiovascular Genetics, IRCCS Istituto Auxologico Italiano, Milano, Italy \\ ${ }^{4}$ Department of Molecular Medicine, University of Pavia, Pavia, Italy \\ ${ }^{5}$ Department of Cardiology, S. Luca Hospital, IRCCS, Istituto Auxologico Italiano, Milano, Italy \\ ${ }^{6}$ Department of Health Sciences, University of Milano-Bicocca, Milano, Italy \\ ${ }^{7}$ Institute of Human Genetics, Helmholtz Zentrum München, Neuherberg, Germany \\ *Corresponding author's e-mail address: m.calcagnino@auxologico.it
}

Published online: 20 February 2015 (version 1)

Cite as: M. Calcagnino et al. ScienceOpen Research 2015 (DOI: 10.14293/S2199-1006.1.SOR-MED.AZGTGZ.v1)

Reviewing status: Please note that this article is under continuous review. For the current reviewing status and the latest referee's comments please click here or scan the QR code at the end of this article.

Primary discipline: Medicine

Secondary discipline: Cardiovascular Medicine

Keywords: Arrhythmogenic cardiomyopathy, Sudden death, Syncope, Ventricular tachycardia, Cardiac magnetic resonance, Desmoplakin, ARVC

\begin{abstract}
Arrhythmogenic Cardiomyopathy is a complex clinical entity, sometimes difficult to diagnose. Three main different patterns of disease expression characterize clinically this hereditary heart muscle disease: the "classic" right ventricular form (ARVC), the "left dominant" subtype (LDAC), with primary left ventricular involvement, and the "biventricular" variant, defined by parallel involvement of both ventricles.

We report on a case of a 51 years old man with a strong family history of juvenile sudden cardiac death of supposed ischaemic origin and personal history of ventricular arrhythmias and supposed myocarditis. We demonstrate how an accurate anamnesis plus correct interpretation of traditional non invasive tests followed by more sophisticate new non invasive tests such as cardiac magnetic resonance and genetic testing allowed to reach the correct diagnosis.
\end{abstract}

\section{CASE DESCRIPTION}

A 51-year-old man presented to our clinic after his son, a previously vigorous and healthy 23-year-old, died suddenly while sleeping.

The patient had a long-standing history of palpitations and syncope leading to frequent accesses to the Accident \& Emergency Department (A\&E), since 1991, when he was 29 years old. In 1995 he had two syncopal episodes. After the first one, his ECG showed evidence of T wave inversion (TWI) in V4-V6 and inferior leads and intraventricular (IV) conduction delay. An Echocardiogram (Echo) showed inferior and postero-lateral left ventricular (LV) wall akynesia with mild LV dysfunction (EF 49\%). Exercise test was normal, with rare single or coupled premature ventricular contractions (PVC). No signs of inducible ischemia were elicited by Dobutamine stress echocardiography. ECG Holter monitoring showed frequent (up to 2000 in 24 hours) monomorphic PVCs organized in couplets or triplets. Tilt table test was normal. After a few months he had another syncopal episode. ECG on arrival at A\&E showed monomorphic sustained ventricular tachycardia (SVT) at $220 \mathrm{bpm}$, with left bundle branch block (LBBB) morphology and superior axis (Figure 1). Sinus rhythm was promptly restored by DC shock. Coronary artery disease was excluded by coronary angiography. Left ventriculography showed mild chamber dilation with diffuse hypokinesia, which was confirmed by Echo with hypokinesia being more evident in the inferior and posterior wall. An electrophysiological (EP) study was performed (drive 500/400 ms, triple extra stimuli up to local refractory period) and at each attempt a polymorphic nonsustained VT (cycle 200/220 ms) was reproducibly induced. However, neither the monomorphic VT seen on the ECG following the syncope nor ventricular fibrillation (VF) was induced. Although myocardial biopsy was not performed, the patient was discharged with a diagnosis of "Ventricular tachycardia in dilated cardiomyopathy likely due to myocarditis."

He was started on Sotalol $80 \mathrm{mg}$ t.i.d., with a reduction of PVC seen at subsequent serial Holter monitoring. He was stable at clinical follow-ups, without additional syncope. 

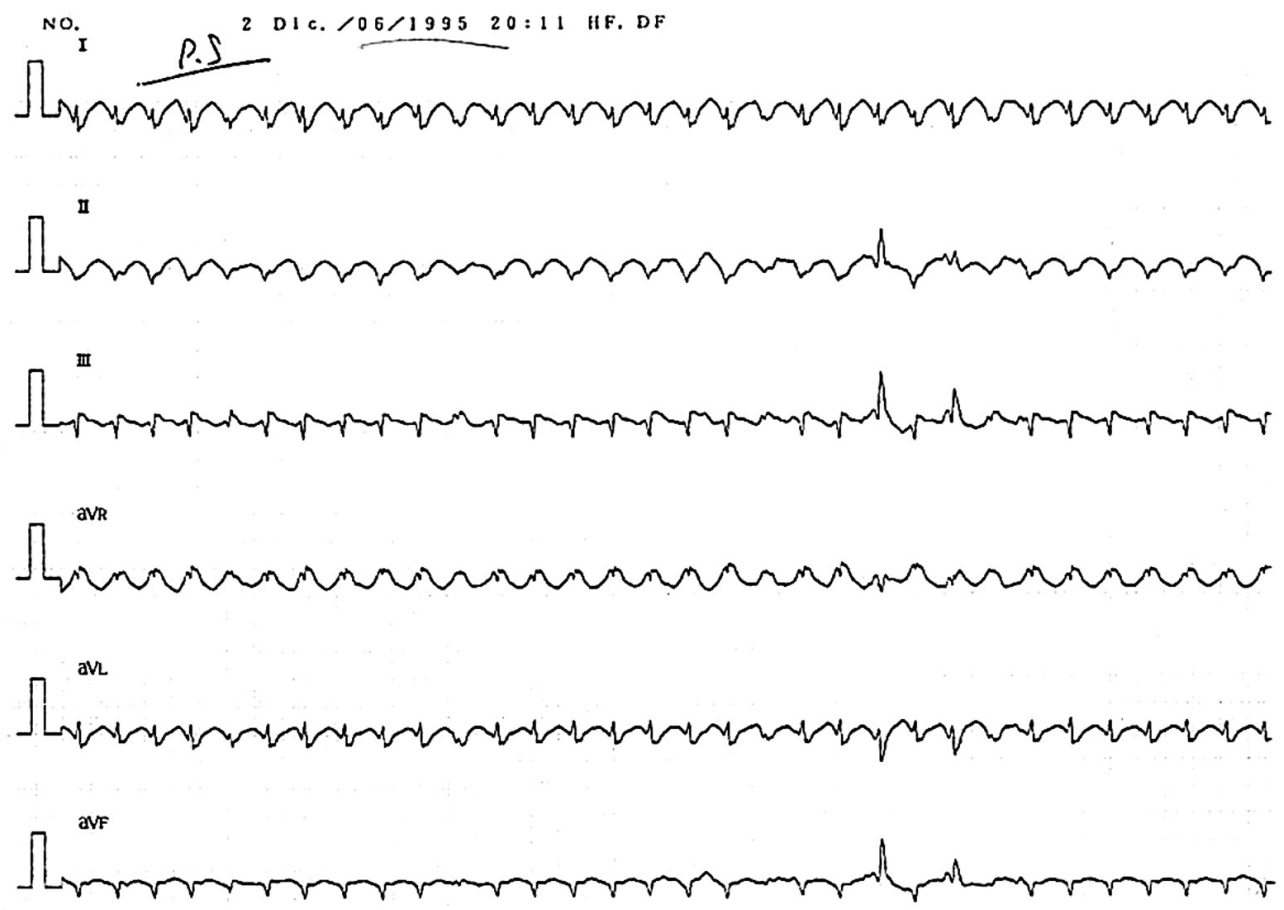

a

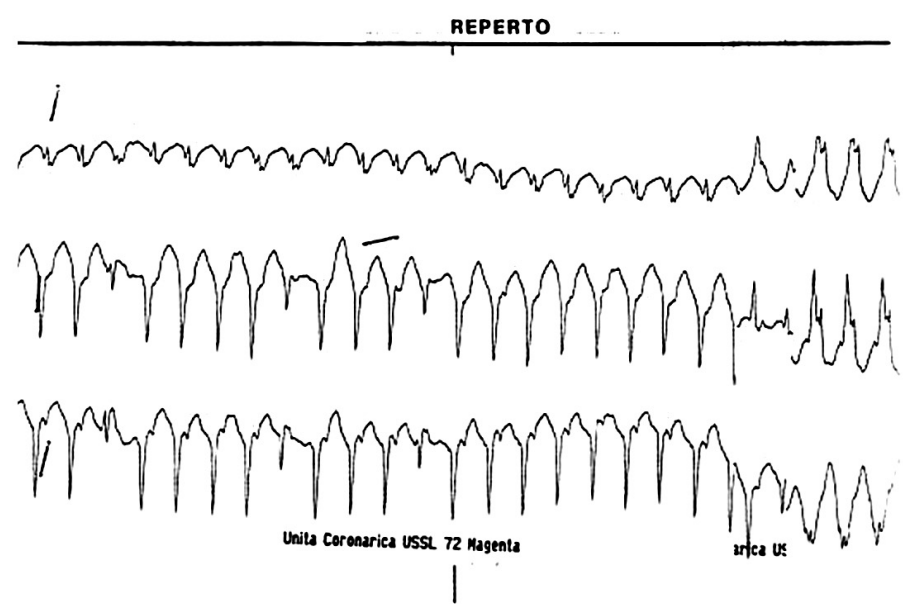

FC:194

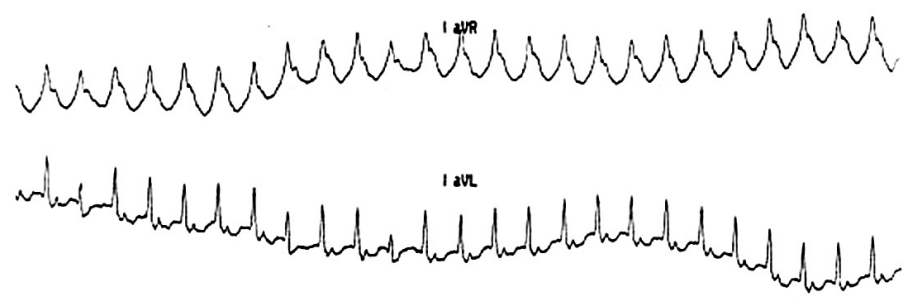

Figure 1. Monomorphic sustained VT at $220 \mathrm{bpm}$, LBBB with superior axis (1995).

When we first examined this patient in 2014, he reported a strong family history of what had always been described by clinicians as sudden death (SD) due to "ischemic heart disease," without any evidence of it. We performed a full noninvasive evaluation of the patient, including resting ECG, Echo,
Holter monitoring, a cycloergometer exercise test and a cardiac magnetic resonance (CMR).

ECG showed sinus rhythm, markedly low voltages, intraventricular conduction delay, and TWI in V4-V6 and inferior leads (Figure 2). Echo showed mildly dilated LV cavity (end 


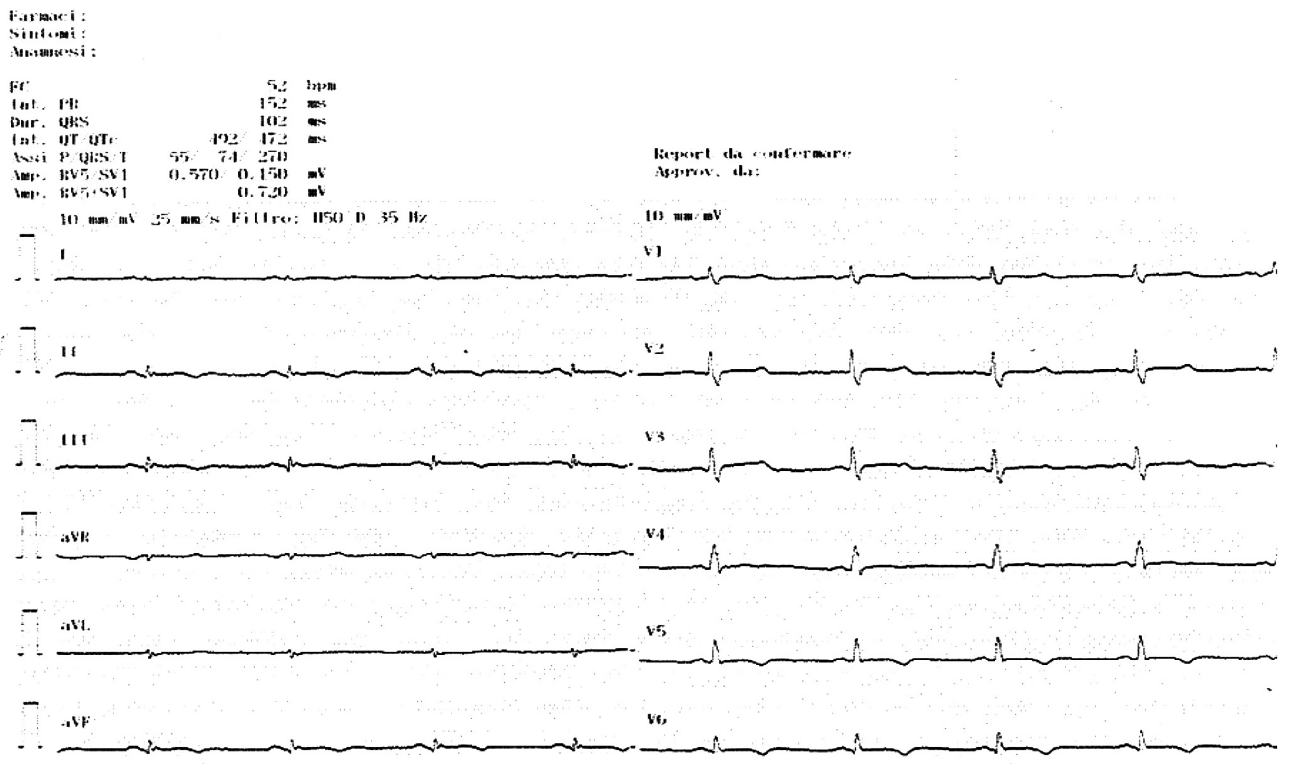

Figure 2. Resting ECG (2014).

diastolic volume $131 \mathrm{ml}, 76 \mathrm{ml} / \mathrm{m}^{2}$ ), mild global hypokinesia, with reduced EF (40\%) and mild diastolic dysfunction. The right ventricle (RV) was also dilated and hypokinetic (RVOT PLAX $40 \mathrm{~mm}$; indexed $23 \mathrm{~mm} / \mathrm{m}^{2}$; TAPSE $17 \mathrm{~mm}$, FAC 37\%), with evident trabeculae in the mid- and apical region and thinning of the free wall. Mild dilation of both atria was also seen. No significant valvular regurgitation by ColorDoppler. Only 575s PVC with a few couplets was recorded at Holter monitoring. Submaximal exercise test, on Sotalol, was interrupted at $74 \%$ of predicted heart rate because of fatigue and dyspnoea, without signs of inducible ischemia, and only a few isolated PVC (LBBB, inferior axis).

Cardiac magnetic resonance confirmed biventricular dilatation (LV EDVi $122 \mathrm{ml} / \mathrm{m}^{2}$; RV EDVi $115 \mathrm{ml} / \mathrm{m}^{2}$ ), with diffuse hypokinesia and reduced ejection fraction (both $\mathrm{EF} \sim 40 \%$ ). Multiple different areas of dyskinesia and bulging were detected in both ventricles. The infero-postero-lateral LV wall was markedly thinned $(2.5 \mathrm{~mm})$. In both ventricles diffuse fibrotic areas were clearly showed by late gadolinium enhancement (LGE) (Figure 3 and Video-clips).

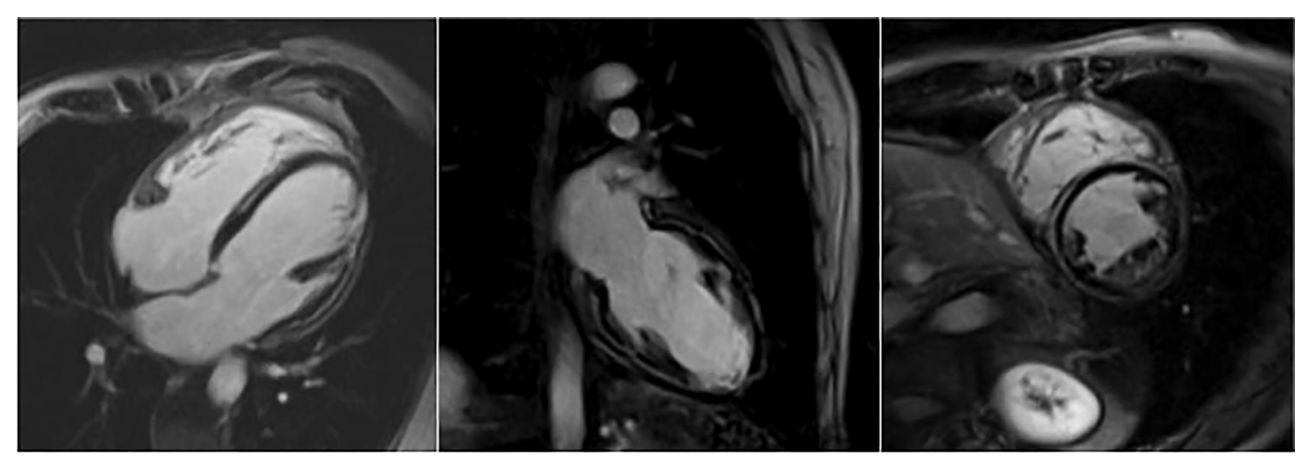

Figure 3. CMR (2014): LGE images (4-chamber, 2-chamber, and short axis views) showing the diffuse intramyocardial and epicardial distribution of fibrotic areas.

Video-clips:

CMR (2014): cine-SSFP images showing biventricular dilatation and systolic dysfunction, with diffuse hypokinesia and multiple different areas of dyskinesia and bulging and thinning of the infero-postero-lateral wall.

Video a. 4-chamber view

Video b. 3-chamber view

Video c. short axis view. 
Based on these findings we diagnosed biventricular arrhythmogenic cardiomyopathy.

Sotalol $80 \mathrm{mg}$ t.i.d. was maintained and Ramipril $5 \mathrm{mg}$ plus Spironolactone $25 \mathrm{mg}$ were added [1]. After careful discussion with the patient, an ICD was also implanted [2,3].

Genetic analysis of the six major ARVC genes (PKP2, DSP, DSC2, DSG2, JUP and TMEM43) was performed through Next Generation Sequencing (TruSeq Custom Amplicon assay, Illumina) on a MiSeq platform. A novel variant in Desmoplakin (DSP, NM_004415.2:c.2878-1G>A) at the canonical acceptor splice site of exon 21 was identified.

To further elucidate the role of this mutation, cascade genetic screening was recommended to family members.

\section{DISCUSSION}

Despite a very aggressive arrhythmogenic pattern, the patient had no clinical signs of disease progression for a long time: neither syncope, cardiac arrest, recurrent SVT, and nor episodes of heart failure. While Sotalol probably protected him from further arrhythmias, structural changes were progressing slowly. Only the contrast CMR was able to completely unveil the extensive fibrous replacement of myocardial tissue in both ventricles.

Nowadays we recognize three patterns of disease expression in patients and families with arrhythmogenic cardiomyopathy: the "classic right ventricular" subtype (ARVC), the "left dominant" variant (LDAC), characterized by early and predominant LV involvement, and the "biventricular" variant, defined by parallel involvement of both ventricles $[4,11,12]$. This clinical entity was first described at postmortem examination in SD victims. Subsequently, LDAC has been observed in families with DSP mutations $[4,11,12]$. We consider that arrhythmogenic cardiomyopathy was likely responsible of the patient's son SD while sleeping. Therefore, a postmortem validation genetic study will be performed in order to confirm the presence of DSP mutation which was identified in his father.

Our patient showed biventricular cardiomyopathy with a strong arrhythmic substrate, given the early presentation with syncopal SVT, with dysfunction and fibrous infiltration of both ventricles seen at CMR and a strong family history of SD: this would represent a straightforward diagnosis of advanced arrhythmogenic cardiomyopathy. However, when the patient was evaluated 20 years ago the picture was not as clear.

His first clinical event was syncope due to SVT probably originating in RVOT tract, and the identification of LV areas of akinesia and mild LV dysfunction by Echo and nonspecific ECG changes were not sufficient at that time for a diagnosis of biventricular arrhythmogenic cardiomyopathy.

Ischemic heart disease was the first working diagnosis but since coronary angiography was unremarkable, and the arrhythmias were not reproduced by an aggressive EP study protocol, a diagnosis of dilated cardiomyopathy was made. However, when the son died suddenly at age 23 the picture changed.

Looking at the clinical data from a different angle we could see that some hints of a more complicated clinical entity were already there from the beginning.

The ECG, a very specific tool if we know what we are looking for, showed markedly low voltages, TWI in the lateral leads, from V4 to V6. The fast SVT recorded after the second syncope had a LBBB with superior axis morphology. These constitute respectively a minor and a major criteria for ARVC, according to the Task Force revised criteria of 2010 [5].

Even taking into consideration all the elements listed above, the whole clinical picture was still pointing toward a disease related to LV. However, the documented symptomatic SVT is somehow atypical if we consider a disease involving only $\mathrm{LV}$ scarring or inflammation, since it usually originates from RV and specifically from the so called "triangle of dysplasia," hence with all the characteristic of being typical for ARVC. The contrast CMR easily clarified the whole clinical picture and made easy the diagnosis. The patient benefited by Sotalol only, which seems to have suppressed the arrhythmias.

The genetic finding is of great interest in this case: a novel, very likely disease-causing mutation, was found on the Desmoplakin gene. Several web-based splice prediction tools (MaxEntScan, NNSPLICE, HSF) [6-8] were used to test the functional consequence of this variant and all predicted abolition of the splice site. Mutations in the splice site consensus sequences have typically functional consequences such as exon skipping, activation of cryptic splice sites or intron retention. Although it is impossible to predict the exact functional consequence without performing in vitro assays on the aberrant mRNA, it is reasonable to assume that the resulting protein will be shorter or truncated. Thus far, very few splice site genetic variants have been described in the DSP gene in the context of ARVC [9]. They are, however, generally interpreted as highly probable disease-causing mutations, as they are either absent or infrequently found in controls [10].

DSP mutations are known to cause ARVC with both primary $\mathrm{RV}$ and $\mathrm{LV}$ involvement $[4,11,12]$. This seems to be in line with other recent findings: a novel truncated DSP mutation has been described as associated with LDAC with primary LV involvement and aggressive phenotype [13].

The lack of specific criteria for AC with primary left- or biventricular involvement, nowadays recognized as a clinical entity per se [4, 11-13], does not allow a correct interpretation of the early signs of complex clinical entities such as these.

The present case is a stark reminder of the need to consider more than a single diagnostic option when facing arrhythmic presentations in young patients and illustrates well the 
growing contribution provided by the genetic laboratory and contrast CMR to clinical management.

\section{REFERENCES}

[1] McMurray JJ, Adamopoulos S, Anker SD, Auricchio A, Böhm M, Dickstein K, Falk V, Filippatos G, Fonseca C, Gomez-Sanchez MA, Jaarsma T, Køber L, Lip GY, Maggioni AP, Parkhomenko A, Pieske BM, Popescu BA, Rønnevik PK, Rutten FH, Schwitter J, Seferovic P, Stepinska J, Trindade PT, Voors AA, Zannad F, Zeiher A, Task Force for the Diagnosis and Treatment of Acute and Chronic Heart Failure 2012 of the European Society of Cardiology, Bax JJ, Baumgartner H, Ceconi C, Dean V, Deaton C, Fagard R, Funck-Brentano C, Hasdai D, Hoes A, Kirchhof P, Knuuti J, Kolh P, McDonagh T, Moulin C, Popescu BA, Reiner Z, Sechtem U, Sirnes PA, Tendera M, Torbicki A, Vahanian A, Windecker S, McDonagh T, Sechtem U, Bonet LA, Avraamides P, Ben Lamin HA, Brignole M, Coca A, Cowburn P, Dargie H, Elliott P, Flachskampf FA, Guida GF, Hardman S, Iung B, Merkely B, Mueller C, Nanas JN, Nielsen OW, Orn S, Parissis JT, Ponikowski P, ESC Committee for Practice Guidelines. ESC guidelines for the diagnosis and treatment of acute and chronic heart failure 2012: the task force for the diagnosis and treatment of acute and chronic heart failure 2012 of the European society of cardiology. Developed in collaboration with the heart failure association (HFA) of the ESC. Eur J Heart Fail. 2012 Aug;14(8):80369. doi:10.1093/eurjhf/hfs105.

[2] Corrado D, Leoni L, Link MS, Della Bella P, Gaita F, Curnis A, Salerno JU, Igidbashian D, Raviele A, Disertori M, Zanotto G, Verlato R, Vergara G, Delise P, Turrini P, Basso C, Naccarella F, Maddalena F, Estes NA 3rd, Buja G, Thiene G. Implantable cardioverter-defibrillator therapy for prevention of sudden death in patients with arrhythmogenic right ventricular cardiomyopathy/dysplasia. Circulation. 2003 Dec;108(25):3084-91.

[3] European Heart Rhythm Association; Heart Rhythm Society, Zipes DP, Camm AJ, Borggrefe M, Buxton AE, Chaitman B, Fromer M, Gregoratos G, Klein G, Moss AJ, Myerburg RJ, Priori SG, Quinones MA, Roden DM, Silka MJ, Tracy C, Smith SC, Jacobs AK, Adams CD, Antman EM, Anderson JL, Hunt SA, Halperin JL, Nishimura R, Ornato JP, Page RL, Riegel B, Priori SG, Blanc, JJ, Budaj A, Camm AJ, Dean V, Deckers JW, Despres C, Dickstein K, Lekakis J, Mcgregor K, Metra M, Morais J, Osterspey A, Tamargo JL, Zamorano JL. ACC/AHA/ESC 2006 guidelines for management of patients with ventricular arrhythmias and the prevention of sudden cardiac death: a report of the American college of cardiology/American heart association task force and the European society of cardiology committee for practice guidelines (Writing Committee to Develop Guidelines for Management of Patients With Ventricular Arrhythmias and the Prevention of Sudden Cardiac Death). J Am Coll Cardiol. 2006 Sep;48(5):e247-346. doi:10.1016/j.jacc.2006.07.010

[4] Protonotarios A, Patrianakos A, Spanoudaki E, Kochiadakis G, Michalodimitrakis E, Vardas P. Left dominant arrhythmogenic cardiomyopathy: a morbid association of ventricular arrhythmias and unexplained infero-lateral T-wave inversion. J Electrocardiol. 2013 Jul-Aug;46(4):352-355. doi:10.1016/j.jelectrocard.2013. 03.011

[5] Marcus FI, McKenna WJ, Sherrill D, Basso CC, Bauce B, Bluemke DA, Calkins H, Corrado D, Cox MG, Daubert JP, Fontaine G, Gear K, Hauer R, Nava A, Picard MH, Protonotarios N, Saffitz JE, Sanborn DMY, Steinberg JS, Tandri H, Thiene G, Towbin JA, Tsatsopoulou A, Wichter T, Zareba W. Diagnosis of arrhythmogenic right ventricular cardiomyopathy/dysplasia: proposed modification of the Task Force Criteria. Eur Heart J. 2010 Apr;31(7):806-14. doi:10.1093/eurheartj/ehq025
[6] Yeo G, Burge CB. Maximum entropy modeling of short sequence motifs with applications to RNA splicing signals. J Comput Biol. 2004;11(2-3):377-94.

[7] Reese MG, Eeckman FH, Kulp D, Haussler D. Improved splice site detection in genie. J Comput Biol. 1997 Fall;4(3):311-23. doi:10.1089/cmb.1997.4.311

[8] Desmet FO, Hamroun D, Lalande M, Collod-Beroud G, Claustres M, Beroud C. Human splicing finder: an online bioinformatics tool to predict splicing signals. Nucl Acid Res. 2009 May;37(9): e67. doi:10.1093/nar/gkp215

[9] van der Zwaag PA, Jongbloed JD, van den Berg MP, van der Smagt JJ, Jongbloed R, Bikker H, Hofstra RM, van Tintelen JP. A genetic variants database for arrhythmogenic right ventricular dysplasia/cardiomyopathy. Hum Mutat. 2009; 30(9): 1278-83. doi:10.1002/humu.21064

[10] Kapplinger JD, Landstrom AP, Salisbury BA, Callis TE, Pollevick GD, Tester DJ, Cox MG, Bhuiyan Z, Bikker H, Wiesfeld AC, Hauer RN, van Tintelen JP, Jongbloed JD, Calkins H, Judge DP, Wilde AA, Ackerman MJ. Distinguishing arrhythmogenic right ventricular cardiomyopathy/dysplasia-associated mutations from background genetic noise. J Am Coll Cardiol. 2011;57(23): 2317-27. doi:10.1016/j.jacc.2010.12.036

[11] Norman M, Simpson N, Mogensen J, Shaw A, Hughes S, Syrris P, Sen-Chowdhry S, Rowland E, Crosby A, McKenna WJ. Novel mutation in desmoplakin causes arrhythmogenic left ventricular cardiomyopathy. Circulation. 2005;112:636-642. doi:10.1161/ CIRCULATIONAHA.104.532234

[12] Sen-Chowdhry S, Syrris P, Prasad SK, Hughes SE, Merrifield R, Ward D, Pennell DJ, McKenna WJ. Left-dominant arrhythmogenic cardiomyopathy: an under-recognized clinical entity. J Am Coll Cardiol. 2008;52(25):2175-87. doi:10.1016/j.jacc. 2008.09.019

[13] López-Ayala JM, Gómez-Milanés I, Sánchez Muñoz JJ, RuizEspejo F, Ortíz M, González-Carrillo J, López-Cuenca D, OlivaSandoval MJ, Monserrat L, Valdés M, Gimeno JR. Desmoplakin truncations and arrhythmogenic left ventricular cardiomyopathy: characterizing a phenotype. Europace. 2014 Dec;16(12):183846. doi:10.1093/europace/euu128

\section{COMPETING INTERESTS}

The authors declare no competing interests.

\section{PUBLISHING NOTES}

(C) 2015 Calcagnino et al. This work has been published open access under Creative Commons Attribution License CC BY 4.0, which permits unrestricted use, distribution, and reproduction in any medium, provided the original work is properly cited. Conditions, terms of use and publishing policy can be found at www.scienceopen.com.

Please note that this article may not have been peer reviewed yet and is under continuous post-publication peer review. For the current reviewing status please click here or scan the QR code on the right.

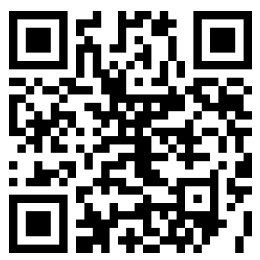

\section{scienceOPEN.com}

